\title{
Caminhos e descaminhos da leitura na escola
}

\section{Paths and dead reading in school}

\section{Catia Toledo Mendonça* \\ Unespar}

Resumo: O trabalho com a leitura nos anos iniciais do Ensino Fundamental deve ser revisto. Nossas crianças leem mal, jovens não gostam de ler. Onde está a raiz do problema? O que fazer? É necessário encontrar alternativas. O caminho atual não é o adequado, como provam os resultados obtidos pelo Brasil no PISA de 2013 - quinquagésimo quinto lugar. 49,2 \% dos alunos que participaram não conseguem passar do nível 2 de leitura, são incapazes de deduzir informações do texto e estabelecer relações entre suas partes. É necessário buscar a gênese do problema, que parece estar na forma como se desenvolve o trabalho com a formação do leitor. A partir de conceitos básicos da teoria literária, da Estética da Recepção, pretende-se, questionar os textos utilizados em sala de aula, como principal fonte do trabalho com a leitura, paradidáticos, em sua maioria, e, portanto, funcionais, embora sejam frequentemente confundidos com o texto literário. Pretende-se também rever a função da contação de histórias na Escola, como atividade importante para a formação do leitor. Finalmente, pretende-se chegar à formação dos professores que atuam nos anos iniciais, percebidos como maiores responsáveis pelo processo de formação de leitores.

Palavras-chave: Leitura. Literatura. Escola.

\begin{abstract}
Work with reading in the early years of elementary school should be revised. Our children read poorly, young people do not like to read. Where is the root of the problem? What to do? It is necessary to find alternatives. The current path is not adequate, as evidenced by the results achieved by Brazil in PISA 2013. $49.2 \%$ of students who participated can not pass level 2 in reading, are unable to deduce information from the text and linking parts. It is necessary to find the genesis of the problem, which seems to be in how the work develops with the formation of the reader. From basic concepts of literary theory, aesthetics of reception, it is intended to question the texts used in the classroom as a major source of work and reading textbooks, mostly, and thus functional, although often confused with the literary text. We also intend to review the role of storytelling in school, as important for the formation of player activity. Finally, we intend to get to the training of teachers working in early years, perceived as most responsible for the training of readers process.
\end{abstract}

Keywords: Reading. Literature. School.

\author{
${ }^{*}$ Dr ${ }^{\mathrm{a}}$ em Estudos \\ Literários pela \\ UFPR-catia.toledo@ \\ fafipar.br Professora \\ na Fafipar/Unespar - \\ Paranaguá - PR
}


Para início de conversa

Dize-me o que lês que te direi quem és.

Eliana Yunes

O ensino da leitura tem servido a propósitos diferentes, dependendo de questões políticas que determinam a função da Escola nas diferentes épocas.

No início do século vinte,em um Brasil ainda rural, onde a alfabetização era restrita a uma elite, ser capaz de ler era um privilégio grande e um status de poucos. Naquela época, as obras escritas para o público infantil refletiam as propostas nacionalistas, de um período marcado pela primeira guerra mundial, quando a necessidade de desenvolver o patriotismo entre as crianças era fundamental. Desse modo, entende-se que Olavo Bilac tenha escrito um poema chamado “A Pátria”, que por muito tempo foi leitura obrigatória nas Escolas de todo país e que, como se percebe pelo trecho a seguir, enquanto era fonte de leitura era também instrumento formador de uma ideologia.

Ama, com fé e orgulho, a terra em que nasceste!

Criança! Não verás nenhum país como este!

Olha que céu! Que mar! Que rios! Que floresta!

A natureza, aqui, perpertuamente em festa,

É um seio de mãe a transbordar carinhos.

Vê que vida há no chão! vê que vida há nos ninhos

Que balançam no ar, entre os ramos inquietos!

Vê que luz, que calor, que multidão de insetos!

Vê que grande extensão de matas, onde impera

Fecunda e luminosa, a eterna primavera! (2009, p.84).

Assim, enquanto a criança aprendia a ler reforçavam-se as imagens exploradas no Romantismo de um Brasil paradisíaco, onde a natureza privilegiada aproximava-se da geografia idílica do Paraíso Terreal, tão procurado pelos navegantes do século XVI, e de um país exemplar, cuja beleza, como apontam os versos de Gonçalves Dias - "Nosso céu tem mais estrelas,/ Nossas várzeas têm mais flores/ Nossos bosques têm mais vida/ Nossa vida mais amores” - , é inigualável. O poema, naquela época celebrado como grande obra de arte do famoso poeta parnasiano, hoje é visto com desconfiança pela crítica, em função de tom altamente ideológico que apresenta. Esse tipo de obra é denominada utilitária, segundo a nomenclatura utilizada por Edmir Perrotti, e embora apresente elementos literários, uma elaboração meticulosa de versos e rimas, seu valor, enquanto texto literário, hoje, é relativizado. 
Como se sabe, ler vem do Latim, legere, que significa “catar”. De acordo com a Estética da Recepção, teoria que centraliza no leitor a construção do texto, este só se realiza totalmente a partir do momento em que é lido, ou seja, o leitor “cata” o sentido que atribui às palavras dentre aqueles que já estão internalizados em sua vivência, em seu conhecimento de mundo. Daí a possibilidade de um mesmo texto ser compreendido de formas diferentes por leitores diferentes, uma vez que cada um traz em si uma bagagem singular, relativa a sua vida. Então, a leitura do texto de Bilac em sala de aula, hoje, seria totalmente diferente da época em que o poema foi escrito, pois nossos alunos, além de desconhecerem boa parte do vocabulário que compõe o poema, não têm em seus registros imagens como a extensão de matas, a presença positiva de insetos ou do calor.

Sob a perspectiva da teoria da Recepção, o bom texto é aquele que deixa espaço para o leitor, para que este atue como co-autor, preenchendo as lacunas com a sua interpretação. Esse seria o leitor-modelo, capaz não só de compreender o texto, mas também de reconhecer nele as marcas deixadas pelo autor, que o levam a penetrar no "bosque dos caminhos que se bifurcam”, metáfora criada por Jorge Luis Borges para designar o texto literário e retomada por Umberto Eco, em sua obra Seis passeios pelos bosques da ficção.

Na Escola, nos anos iniciais do Ensino Fundamental, o trabalho com esse tipo de texto, que permite ao leitor preencher seus espaços, é muito raro. Sob a perspectiva pedagógica, o bom texto é aquele que "ensina algo" e, por isso, são textos em que não há espaços a serem preenchidos pelo leitor, uma vez que as noções que se deseja passar com a leitura devem estar óbvias, claras, como no poema de Bilac.

Nessa mesma escola, deveriam ser desenvolvidos, pelo menos, dois tipos de leitura: a instrumental e a literária. A leitura instrumental é aquela que fazemos todos os dias. Lemos placas de rua, lemos avisos nas paredes, instruções para provas, ou seja, lemos para alcançar alguma finalidade. Esses textos são chamados “funcionais”, são pragmáticos, didáticos, e exigem do leitor pouco mais que sua capacidade de decifrar o código usado para sua elaboração. É claro que é necessário conhecer o vocabulário e ser capaz de estabelecer relações entre o significante e o significado de cada palavra, condição básica para que a leitura se realize no “catar” de sentidos. Depois que o leitor percebe e decifra os signos, ele tenta entender do que se trata. Ora, os textos funcionais são sempre escritos "para” alguma coisa, têm uma função estabelecida e, por isso, não podem deixar dúvidas quanto a esse objetivo. Por exemplo: "Nossa, parece até que você ficou rolando na lama! É muito bom brincar! Mas a festa do Téo está chegando e não dá para ir sujo desse jeito... Vamos tomar banho? Sai, sujeira!” (MANNING e GRANSTROM, 2002, p.26). 
Como se pode perceber, o trecho acima que faz parte de Sai, sujeira, escrito por Mick Manning e Brita Granstrom, foi criado com uma finalidade bem evidente: ensinar hábitos de higiene a crianças e apesar de o livro ser muito bem diagramado e ilustrado, não é um texto literário. Nenhum leitor terá dúvidas quanto à sua finalidade, expressa numa linguagem pretensamente objetiva, sem nenhum rebuscamento ou elaboração que a aproxime de um texto artístico.

Esse tipo de leitura é a que mais se encontra na Escola. Ela é importante, uma vez que transmite valores, hábitos e atitudes desejáveis para as crianças, mas não deve ser confundida com a leitura literária, que exige habilidades diferentes do leitor.

A leitura literária se dá a partir de textos plurisignificativos, com os quais o leitor estabelece um diálogo e lhes atribui função. Não são textos escritos “para” algo, são obras de arte, assim como um quadro ou uma música, e é por isso mesmo que são, como afirma Paulo Leminski, "inutensílios”, pois não têm uma finalidade determinada a partir do autor. O leitor é que ao lê-los poderá identificar-se com aquilo que lê e passar a ver neles uma referência à qual recorrerá sempre que achar necessário. Tome-se como exemplo o trecho a seguir, retirado da obra de Bartolomeu Campos Queirós: “Difícil não conferir razão a meu pai em seus momentos de anjo. Ele pendia a cabeça para a esquerda, como se escutando o coração e falava sem labirintos. Dizia frases claras, acordando sorrisos e caminhos” (1986, p.7).

Embora o texto não apresente palavras de difícil compreensão para leitores de um quarto ano, por exemplo, a organização dessas palavras no texto é singular e cria imagens, metáforas que exigem do leitor a associação de idéias, como para que entenda o que são os "momentos de anjos" do pai ou o que significa "falar sem labirintos" e "acordar sorrisos e caminhos”. Essas construções apontam o trabalho artístico do autor, que apesar de estar falando sobre as lembranças da infância o faz de forma poética, utilizando-se de uma linguagem especial, diferente daquela usada no dia-a-dia, ou seja, a linguagem literária.

Observe-se que o aluno alimentado somente com textos funcionais não terá condições de, ao se deparar com um texto literário como esse de Bartolomeu Queirós, lê-lo, pois não estará preparado para estabelecer as relações exigidas. Deste modo, é quase certo que abandone a leitura, alegando que não entendeu nada ou que o livro é “chato”.

Chegamos então a um ponto crucial da questão da leitura: nossos alunos são “treinados” para ler um único tipo de texto, o funcional, e , por isso, não conseguem entender as leituras de textos literários que se apresentam, geralmente, só por volta dos últimos anos do Ensino Fundamental. Alimentados apenas com textos fáceis, em nome de uma "ditadura do gosto” que marca a Escola brasileira, as crianças são acostumadas com 
textos que pouco exigem do leitor e quando se deparam com a complexidade de um texto literário, tornam-se analfabetos. Embora a falta de contato com o texto literário não seja o único problema a dificultar o desenvolvimento do processo de leitura de nossos alunos, este é, sem dúvida, um ponto de extrema importância, pois a leitura literária, além de preparar o leitor para perceber os vários níveis que compõem o texto, contribui para a formação do indivíduo, levando-o a ter contato com outras possibilidades de organização social, outras culturas e, por isso mesmo, tornando-o crítico em sua forma de lidar com a realidade. A criança alimentada com textos literários de qualidade estará mais preparada para lidar com o mundo e com o universo da leitura.

Deve-se somar a esse quadro o despreparo do professor no que tange o texto literário. Nas faculdades de formação de professores, em particular nos cursos de Pedagogia, o conceito de texto literário passa longe das teorias literárias. Percebe-se a confusão entre o pedagógico e o literário como um completo desconhecimento das particularidades que os diferenciam. No contato com professores, na sua maioria da rede pública de Curitiba, percebe-se a surpresa destes quando são apontadas as características de cada texto, revelando que o trabalho inadequado não é fruto de displicência ou má vontade dos docentes, mas de seu completo despreparo para atuar criticamente nesse campo.

Por desconhecerem critérios de seleção do texto literário, os professores são levados à adoção de obras que atendam aos temas transversais, que passem “valores” aos alunos, que permanecem ligados a uma visão ultrapassada da literatura infantil, quando se entendia que as obras infanto-juvenis deveriam atender a questões ideológicas, como o texto de Bilac ou como os textos que se consagraram na década de setenta, quando vários autores influenciados pelas teorias de correntes da Psicologia, criaram obras nas quais o leitor era levado a assumir comportamentos de enfrentamento com o adulto, como acontece em Raul da ferrugem azul, de Ana Maria Machado, classificada por Perrotti como "utilitária às avessas”, por apresentar valores inversos às chamadas utilitárias, como o poema de Bilac.

Ana Maria Machado, hoje representante da LIJ na ABL, deixou de lado essa tendência e é dos grandes referenciais da literatura feita para crianças e jovens no Brasil, mantendo- se distante dos temas transversais e comprometida com o texto estético, como se pode perceber nas muitas obras de alta qualidade literária dessa autora.

O mesmo não se pode dizer de Ruth Rocha, presença constante na Escola, e autora de uma obra extremamente cambiante, na qual se unem encomendas feitas pelas editoras- leia-se “Escola”-, adaptações redutoras, como a de As mil e uma noites, publicada sob o título de Histórias das mil e uma noites e obras consagradas, como Marcelo, marmelo, martelo, um grande referencial da literatura infantil da década de setenta, embora claramente ligada à tendência utilitária às avessas. 
Esta autora, apesar de sua consagração pela Escola, está claramente ligada à tendência utilitária, na qual se percebe a falta de preocupação com o estético, a utilização de uma linguagem simplista, às vezes pretensamente infantil, que nada acrescenta ao leitor, que não contribui para sua formação, nem como sujeito leitor nem como sujeito social.

Estudos da Sociologia da Leitura apontam para a importância de ouvir histórias na infância, como um dos fatores significativos quando o assunto é formação do leitor. Na sociedade atual, o contador de histórias ocupa lugar diferente daquele que lhe era reservado na tradição dos grandes narradores. Hoje contar histórias é uma profissão, mas os narradores de que falava Walter Benjamim, estão desaparecendo. Nem mesmo a figura das mulheres narradoras, durante tantos anos simbolizadas pela avó, hoje é facilmente encontrada. Desta forma, cada vez mais cabe à Escola a função de, a partir da contação de histórias, estimular a formação do leitor.

Apesar do valor inquestionável dessa atividade, na Escola, de modo geral, contar histórias ainda é vista como uma atividade de valor secundário. Desconhecedores da importância de ouvir histórias para o desenvolvimento da imaginação e da inteligência infantil, muitos docentes as contam apenas quando sobra um tempinho da aula, ou então para que os alunos, após ouvi-las, desenhem, criem maquetes, elaborem personagens com massinha ou qualquer outra atividade semelhante.

Essa prática é tão constante que os próprios alunos já associaram as histórias a um depois e quando a professora não apresenta uma proposta de atividades depois, os alunos são capazes de questionar se não irão “fazer nada”.

Esse procedimento é incentivado pela Pedagogia que, na figura do pedagogo presente nas escolas, cobra as atividades de registro, reduzindo assim a importância da história como uma atividade de alto valor, vendo-a como uma preparação para outra.

Bruno Bettelhein, em obra publicada na década de oitenta A psicanálise dos contos de fadas - destaca o valor da literatura na formação da criança. Ele afirma que "para não ficar à mercê dos acasos da vida, devemos desenvolver nossos recursos interiores, de modo que nossas emoções, imaginação e intelecto se ajudem e se enriqueçam mutuamente”(BETTELHEIM, 1986, p. 12) e que "nada é tão enriquecedor e satisfatório para criança, como para o adulto, do que o conto de fadas folclórico”. O psicanalista segue explicando a importância das histórias para as crianças, de como elas se desenvolvem a partir das identificações que fazem entre seus conflitos interiores e os fatos narrados pelos contos e de como isso ajuda a ordenar sentimentos e entender-se, sem que seja necessário explicitar conceitos numa moral “edificante”. Segundo Bettelheim, a criança encontra, nos contos de fadas, os significados profundos da vida, que a ajudarão a responder questões sobre a razão de sua própria existência, 
implícitos numa linguagem simbólica, que permite à criança armazenar sugestões e “crescer a salvo para a maturidade”(BETTELHEIM, 1986, p.15).

Outro assunto que o psicanalista e educador destaca é a importância da presença do Mal nos contos de fadas. É através do contato com essas histórias que a criança aprende a lidar com o Mal, pois "nos contos de fadas, como na vida, a punição ou o temor dela é apenas um fator limitado da intimidação do crime”(BETTELHEIM, 1986, p.15) e a leitura leva a criança a sofrer com o herói, a se identificar com a sua luta, a tornar-se vitorioso com ele, vitória com a qual o leitor se identifica e internaliza para sua vida. É por isso que nos contos de fadas a pessoa má sempre perde, é punida e a criança não discorda dessa punição.

Aimportância das histórias é tal que, ainda hoje, há quem reflita sobre isso. Publicada em 2006, a obra Fadas no divã, de autoria dos psicanalistas gaúchos Diana e Mário Corso, continua a discussão de Bettelheim e a estende para outros contos, assim como para as narrativas mais contemporâneas, como Pinochio, Peter Pan, Harry Potter e até Mafalda e Calvin, personagens nos quais os autores destacam a artificialidade em relação às crianças leitoras. A publicação dessa obra reforça a importância da presença das histórias na vida das crianças que, hoje, têm quase que exclusivamente a figura da professora como contadora de histórias.

Apesar dos estudos que referendam a importância de a criança ter contato com os contos de fadas em sua forma original, estes têm sofrido restrições pedagógicas e alguns de seus elementos alterados, em nome de um "politicamente correto”, que mexe com a estrutura profunda das histórias e muitas vezes deixa de cumprir suas funções primordiais. Lobos que são mandados para o zoológico amenizam a punição do vilão, assim como uma vovozinha presa num armário mantém a criança longe da crueldade cometida pelo lobo, que não só a devora como induz a neta a comer parte de sua carne, na versão original, de 1697. É também diferente da continuação criada pelos irmãos Grimm, que, dando seqüência à história, inserem a figura de um lenhador que, passando em frente à casa da vovó, encontra o lobo dormindo com a barriga cheia, abre-a e retira vivas, a vovó e sua neta e, em seu lugar, coloca pedras.O lobo, acordando, sente muita sede, vai beber água no riacho e acaba se afogando, ou seja sofre a punição que merece pelos crimes cometidos.

A retirada desses elementos, assim como as alterações verificadas nos contos Cinderela e A bela adormecida, fazem parte de uma amenização exigida pela pedagogia moderna e que contrasta terrivelmente com a violência encontrada nos vídeo-games ou em notícias dos jornais televisivos, que todos os dias invadem as casas para falar de crianças atiradas pela janela pelos pais, fato muito mais ameaçador para a criança do que o contato saudável com os contos de fadas. 
Outra prática bastante constante em salas de aula é a substituição de palavras encontradas nos textos por outras de valor semântico semelhante, mais próxima do vocabulário das crianças. Ao trocar palavras, o professor não só está alterando o texto original e, portanto, tornando-se também autor daquele texto, como está impedindo a criança de conhecer novas palavras, de aumentar seu vocabulário, pois, com certeza, se houver uma palavra que ela desconheça, ao contrário dos adultos que ficam intimidados, a criança não terá problemas em perguntar o significado. Marina Colasanti, em passagem pela cidade de Curitiba, ao apresentar-se no Paiol Literário, manifestou seu desapreço por tal atitude ${ }^{1}$. Chegou a dizer que preferia que não contassem suas histórias, pois ao trocar palavras os professores inutilizam seu trabalho cuidadoso de escolher cada uma delas para compor as suas “pérolas”, como a autora denomina os seus contos de fadas.

Outro aspecto dessa mesma questão que deve ser levantado é a escolha das histórias a serem contadas. É muito comum que os professores se limitem a contar as histórias consagradas pela mídia, que se transformaram em filmes ou foram editadas pela Disney. Esse procedimento deixa de lado um número infinito de contos interessantíssimos, compilados tanto por Perrault, no século XVII, quanto pelos irmãos Grimm, cem anos mais tarde. Ambos juntaram mais de uma centena de contos cada um, sem falar naqueles criados por Andersen, perfazendo um total de mais de três centenas de histórias, reduzidas a umas poucas em sala de aula, o que também reduz muito as possibilidades de encantamento com o novo por parte das crianças ouvintes, submetidas sempre aos mesmos textos. Além disso, cada texto traz em si questões diferentes a serem trabalhadas internamente pelas crianças, como nos mostra Bettelheim, e a limitação das histórias limita também o trabalho interno das pequenas criaturas.

Há também um sem número de histórias folclóricas oriundas dos mais diversos cantos do mundo que, por terem surgido da tradição oral, trazem em si valor simbólico semelhante aos conhecidos contos de fadas e permitem aos ouvintes o contato com outras culturas, outras realidades diferentes daquelas com as quais as crianças estão acostumadas e, portanto, novas possibilidades de lidar com os conflitos pessoais.

Celso Sisto, em sua obra Textos e pretextos sobre a arte de contar histórias, dedica metade do livro a um “olhar pedagógico” e um capítulo inteiro ao professor, que ele denomina “Contação de histórias- para jovem gostar de ler” (SISTO, 2001, p. 99), no qual destaca a importância de o professor ser leitor, para que possa “desenvolver o gosto pela leitura”, para que se torne um professor agente de leitura, se aproxime dos alunos e os aproxime do mundo da leitura. Sisto também destaca a importância de selecionar bem o texto e "utilizar conscientemente os recursos de instrumental humano (emoção, corpo, voz, memória) e os recursos técnicos necessários para uma maior eficácia no trabalho com a palavra
Palestra proferida no dia 12 de março, de 2008, no teatro Paiol, em Curitiba, como parte integrante do projeto Paiol Literário. 
(naturalidade, ritmo, entonação, pausas)” (SISTO, 2001, p. 101). Como se percebe, a contação de histórias envolve toda uma preparação, que começa na escolha do livro - deve-se escolher uma história que seja bem construída e que apresente características que a tornem um texto literário- e se estende ao ato de contar, o qual, segundo Sisto, deve ser inusual, para que seduza o aluno. Daí a necessidade de preparar antes, mesmo que seja uma simples leitura, para que esta não seja vista como parte das leituras informativas feitas no dia-a-dia.

Desse modo, investe-se o ato de contar histórias da importância que ele deve ter, como elemento fundamental no processo de formação do leitor, e prepara-se o aluno para que compreenda melhor a estrutura de uma narrativa qualquer, até mesmo de um texto literário.

\section{Considerações finais}

Os problemas com a leitura em sala de aula estão, ainda, longe de serem resolvidos. É necessário que se reavalie todo o processo de formação do leitor e que sejam feitas alterações sérias nesse campo, sem as quais o quadro não irá se alterar.

Não se trata aqui de encontrar "culpados”, mas de buscar alternativas para que se reverta esse quadro vergonhoso que é a leitura no Brasil. Muito se tem dito sobre a importância da educação para o desenvolvimento de um país, para que se criem cidadãos conscientes e críticos, que saibam valorizar sua pátria, mas que aprendam isso não com a leitura de textos doutrinantes, e sim com obras que lhes permitam conhecer outras possibilidades de organização social, para que possa realmente escolher aquela em que quer viver.

O trabalho com o texto literário em sala de aula, se não vem solucionar todas as questões, apresenta alternativas que ajudam a minimizar as dificuldades dos alunos, além de contribuir para o crescimento de seus repertórios, quesito indispensável que para se estabeleçam relações e o ato de “catar” possa se efetivar. Além disso, como afirma Bettelheim, o contato com as histórias infantis permite à criança o seu crescimento interno, o desenvolvimento enquanto pessoa, de forma saudável, sem que sejam necessárias morais explícitas que o induzam a este ou àquele comportamento.

A figura do contador de histórias, tradicionalmente feminina, que antigamente era registrada pela mãe, pela avó das crianças, hoje é tributo do professor, de um modo geral ainda mulher, nos anos iniciais, que deve se adequar para o desenvolvimento da nova função. Somente conhecendo a importância dessa atividade é que os professores poderão levá-la a cabo de forma satisfatória, podendo, inclusive, passar a ter prazer também eles, no contato com o mundo da fantasia, para o qual a expressão "Era uma vez...” abre as portas. 
O professor, essa figura fundamental em qualquer sociedade, tem sido desprestigiado em nosso país, não só na valorização de seu trabalho no que diz respeito a salários, mas também na falta de percepção de sua importância da cadeia de profissões, uma vez que sem passar por um professor dos anos iniciais, ninguém chega a ser engenheiro, médico ou publicitário, profissões que hoje estão no topo das aspirações juvenis.

No entanto, nesses tempos de Internet, de imagens em Ipads, nada substitui a presença de uma pessoa a contar histórias para os pequeninos, seja na hora de dormir, seja ao final da manhã ou da tarde, e essa figura hoje não é a tia, mas é a professora, que merece receber a formação adequada para o desenvolvimento desse importante papel que lhe cabe na sociedade e contribuir efetivamente para a formação de pessoas melhores e também de um país melhor.

\section{Referências}

BETTELHEIM, B. A psicanálise dos contos de fadas. Tradução de Arlene Caetano. 6ed. Rio de Janeiro: Paz e Terra, 1986.

BILAC, Olavo. Poesias infantis. São Paulo: Empório dos livros, 2009.

CORSO, D \& M. Fadas no divã. Porto Alegre: Artmed, 2006.

ECO, U. Seis passeios pelos bosques da ficção. Tradução de Hildegard Feist. São Paulo: Ática, 1994.

MANNING, M. \& GRANSTROM, B. Sai, sujeira! Tradução de Marta Svartman. São Paulo: Ática, 2002.

PERROTTI, E. O texto sedutor na literatura infantil. São Paulo: Ícone, 1986.

QUEIRÓS, Bartolomeu Campos. Ler, escrever e fazer conta de cabeça. Belo Horizonte: Miguilim, 1986.

SISTO, C. Textos e pretextos sobre a arte de contar histórias. Chapecó: Argos, 2001.

YUNES, Eliana citada por Morais, Marta. Mapa do Mundo: crônicas sobre leitura. Belo Horizonte: Editora Leitura, 2006.

Recebido em 20/11/2013

Aprovado em 05/02/2014 